\title{
Perspective
}

\section{Challenges for Policy Makers and Organizational Leaders: Addressing Trends in Mental Health Inequalities}

\author{
Christy A. Rentmeester \\ Center for Health Policy and Ethics, School of Medicine, Creighton University, Omaha, Nebraska, USA
}

Received: 1 July 2013, Accepted: 17 July 2013, ePublished: 20 July 2013

\section{Abstract}

We typically think of acutely and chronically mentally ill patients as those who belong in psychiatric hospitals and the latter category of patients belonging in "regular" hospitals, but the intersection of physical and mental illness draws attention to important challenges for policy makers and organizational leaders. This article illuminates some broad trends in the health status of people with mental illnesses, canvasses important features of inequalities suffered by people with mental illnesses, and suggests strategies for systemic reform. Most reform recommendations I offer are in the area of healthcare organization leadership and management. Other key reforms will likely be legislative, regulatory, and insurancerelated. Social and cultural reforms in organizational practices and structures will also be critical.

Keywords

Mental Health, Inequality, Policy Making, Systematic Reform

Physical illness among people with mental illnesses

Globally, mental illnesses constitute about 14\% of disease burden (1). Patients with mental illnesses have more physical illnesses than do patients without mental illnesses (2-6), and the breadth and severity of medical problems among patients with mental illnesses are not well known $(7,8)$. Some populationbased evaluations of mentally ill people with physical illnesses suggest a lack of standardized assessments of needs, failure to address a plurality of competency standards, and contradictory findings are common methodological limitations to studying illness among members of this population $(9,10)$. Medications for physical illnesses can have a range of psychiatric effects (5) and medications for mental illness can have a range of iatrogenic physical effects (2) that can generate medical comorbidity.

Inequalities: Challenges for policy makers and organizational leaders

Health status, premature death

Risk of premature death is certainly one faced by people with mental illnesses, who have earlier mortality rates $(3,11)$ than the general population. People with mental illnesses also suffer more preventable illness $(3,12)$ than the general population. Risk of premature death is increased due to natural causes
$(2,3,13,14)$, and also to unnatural causes, such as accidents or suicide $(2,15)$. Mental illnesses are also a leading cause of disability $(16,17)$.

\section{Less access to healthcare, lower quality healthcare}

People with mental illness have restricted access to medical care $(4,5)$. Important barriers to care include high costs of care and difficulty obtaining insurance $(2,18)$. When they do get care, people with mental illness also receive inferior healthcare relative to members of the general population (2,3,19-22). Racial and ethnic inequalities in access to and quality of mental health care also persist (23).

\section{Recommendations for systemic reform}

The necessity for both physical and mental healthcare in an efficient, quality healthcare system is widely recognized $(16,24)$. The importance of changing mental health policy such that emergency, outpatient, and inpatient mental health services are reimbursed at levels that allow for the sustainability and growth of such services is also widely recognized (16,25). Parity in mental health payments from insurers is obviously essential toward promoting health justice. Achieving parity will require cross-disciplinary commitment and collaboration. Table 1 below summarizes some of the critical areas that can contribute to improved policy and practice in mental healthcare.

Perhaps the broadest recommendation for systemic reform relates to a social and cultural shift we must make from seeing patients with mental illness in terms of their capacities to threaten themselves or others to seeing them in terms of their vulnerabilities. The current rise-to-the minimum, de facto standard of admitting patients for inpatient psychiatric care from emergency departments only when they are dangerous to themselves or others, sometimes known as the endangerment criterion, must quickly evolve to respond more capaciously to the needs of people with mental illnesses who are vulnerable and in trouble. It is easy to see here how the social and cultural shifts must work "hand-in-hand" with the reforms needed from insurance and organizational management structures. For example, reform evolution will require cultural and social support to end the persistent "bed crises"-the unavailability

${ }^{\star}$ Corresponding author: Christy A. Rentmeester; Email: christyrentmeester@creighton.edu 
Table 1. Key policy areas and reform recommendations

\begin{tabular}{|c|c|}
\hline $\begin{array}{l}\text { Area of mental health care } \\
\text { policy }\end{array}$ & Reform recommendations \\
\hline \multirow{2}{*}{ Social and cultural } & $\begin{array}{l}\text { Implement transition from seeing patients with mental illness in terms of their capacities to threaten themselves } \\
\text { or others to seeing them in terms of their vulnerabilities. }\end{array}$ \\
\hline & $\begin{array}{l}\text { Implement transition from the endangerment criterion for admitting patients for inpatient psychiatric care to a } \\
\text { standard that prioritizes the vulnerabilities and needs of people with mental illnesses. }\end{array}$ \\
\hline \multirow{2}{*}{ Insurance } & Implement requirements for payment parity in mental health and general health claims. \\
\hline & Eliminate "carve-outs" in health services coverage. \\
\hline \multirow{5}{*}{$\begin{array}{l}\text { Healthcare organization } \\
\text { leadership and } \\
\text { management }\end{array}$} & $\begin{array}{l}\text { Draw upon hospitals' and clinics' status as sites of major medical and surgical care to promote sustainable } \\
\text { reimbursement rates for mental health services. }\end{array}$ \\
\hline & $\begin{array}{l}\text { Partner with community-based mental health service providers to mitigate stigma, promote efficiency, and } \\
\text { support care-continuity for people with mental illnesses. }\end{array}$ \\
\hline & Explore strategies for cultivating philanthropic sources of revenue to fill gaps in mental health service provision. \\
\hline & $\begin{array}{l}\text { Recruit recovered patients, advocates, and professional caregivers for leadership roles in meeting with } \\
\text { philanthropists to motivate responsive health promotions practices in communities. }\end{array}$ \\
\hline & $\begin{array}{l}\text { Implement programs focusing on clinicians' practices of clinical moral perception }(26,27) \text { to help caregivers resist } \\
\text { viewing patients with mental illness as "difficult" and to help caregivers maintain compassionate views toward } \\
\text { patients. }\end{array}$ \\
\hline \multirow[b]{2}{*}{ Legislative and regulatory } & Leverage public policy changes that respond to needs of the most vulnerable citizens. \\
\hline & $\begin{array}{l}\text { Pursue closer monitoring of iatrogenic effects of medications that impact physical health of people with mental } \\
\text { illnesses over the long term. }\end{array}$ \\
\hline
\end{tabular}

of infrastructure, space, staff, and resources to care for persons with mental illnesses in trouble-and appropriation of support to professional and nonprofessional caregivers of people with mental illnesses.

Clinically, there are also important roles individual healthcare professionals can assume in improving physical and mental health services for patients with mental illness. Several experts call for closer monitoring of iatrogenic effects of antipsychotic medications, such as weight gain or elevated glucose and lipid levels, for example (28-32). Both clinically and ethically relevant is a reminder that the behaviours or symptoms of a person with mental illness "are not expressions of the patient's desire or right to be difficult but are rather driven by symptoms from which the patient suffers uncomfortably, even if those symptoms seem to be preferred or sought by the patient" (33).

A critical insurance reform is elimination of "carve-outs," and hospitals and other healthcare organizations have important leadership roles in motivating this reform. Specifically, hospitals and clinics, for example, can draw upon their status as sites of major medical and surgical care to promote sustainable reimbursement rates for mental health services (16). Hospitals can also partner (16) with smaller community-based mental health service providers to mitigate stigma and promote efficiency and care-continuity for people with mental illnesses. Both hospitals and individual departments, say psychiatry, can explore strategies for cultivating philanthropic sources of revenue to respond to needs to fill gaps in mental health service provision (16). Professional caregivers, recovered patients, and advocates can all assume leadership roles in meeting with philanthropists to motivate cases for promoting responsive public health and health justice in communities. Finally, legislatures and regulators must leverage change by framing public policies (34) that prioritize and respond directly to the needs of some of our most vulnerable residents and neighbours.
Ethical issues

Not applicable.

Competing interests

None.

Author's contribution

CAR is the single author of the manuscript.

\section{References}

1. Prince M, Patel V, Saxena S, Maj M, Maselko J, Phillips MR, et al. No health without mental health. Lancet 2007; 370: 859-77.

2. Osborn DP. The poor physical health of people with mental illness. West J Med 2001;175: 329-32.

3. Felker B, Yazel JJ, Short, D. Mortality and medical comorbidity among psychiatric patients: a review. Psychiatr Serv 1996; 47: 1356-63.

4. Goldman LS. Comorbid medical illness in psychiatric patients. Current Psychiatry Report 2000; 2: 256-63.

5. Lyketsos CG, Dunn G, Kaminsky MJ, Breakey WR. Medical comorbidity in psychiatric inpatients: Relation to clinical outcomes and hospital length of stay. Psychosomatics 2002; 43: 24-30.

6. Maricle R, Hoffman W, Bloom J, Faulkner L, Keepers G. The prevalence and significance of medical illness among chronically mentally-ill outpatients. Community Ment Health J 1987; 23: 81-90.

7. Pavalonis D, DeCarr M, Shutty M. Nursing roles for chronic pain management in the seriously mentally ill. J Am Psychiatr Nurses Assoc 1995; 1: 107-11.

8. Farmer S. Medical problems of chronic patients in a community support program. Hosp Community Psychiatry 1987; 38: 745-9.

9. Appelbaum PS, Grisso T. The MacArthur Treatment Competence Study III: Abilities of patients to consent to psychiatric and medical treatments. Law Hum Behav 1995; 19: 149-74.

10. Candilis PJ, Foti ME, Holzer JC. End-of-life care and mental illness: A model for community psychiatry and beyond. Community Ment Health J 2004; 40: 3-16.

11. Dembling BP, Chen DT, Vachon L. Life expectancy and causes of 
death in a population treated for serious mental illness. Psychiatr Serv 1999; 50: 1036-42.

12. Bonhoeffer K. Die psychosen im gefolge von akuten infektiouen allgemeiner krankungen und inneren erkrankungen. Handbach der Psychiatrie (Ed. Aschaffenburg GL). Deuticke: Leipzig, Germany; 1912. 13. Jeste DV, Gladsjo JA, Lindamer LA, Lacro JP. Medical comorbidity in schizophrenia. Schizophr Bull 1996; 22: 413-30.

14. Harris EC, Barraclough B. Excess mortality of mental disorder. $\mathrm{Br} J$ Psychiatry 1998; 173: 11-53.

15. Schulz R, Beach SR, Ives DG, Martire LM, Ariyo AA, Kop WJ. Association between depression and mortality in older adults: the Cardiovascular Health Study. Arch Intern Med 2000; 160: 1761-8.

16. Liptzin B, Gottlieb GL, Summergrad P. The future of psychiatric services in general hospitals. Am J Psychiatry 2007; 164: 1468-72.

17. Iglehart J. The Mental Health Maze and the Call for Transformation. N Engl J Med 2004; 350: 507-14.

18. Druss BG, Rosenheck RA. Mental disorders and access to medical care in the United States. Am J Psychiatry 1988; 155: 1775-7.

19. Young JK, Foster DA. Cardiovascular procedures in patients with mental disorders. JAMA 2000; 283: 3198-9.

20. Druss BG, Bradford DW, Rosenheck RA, Radford MJ, Krumholz HM. Mental disorders and use of cardiovascular procedures after myocardial infarction. JAMA 2000; 283: 506-11.

21. Kendrick T. Cardiovascular and respiratory risk factors and symptoms among general practice patients with long-term mental illness. $\mathrm{Br} J$ Psychiatry 1996; 169: 733-9.

22. Karasu TB, Waltzman SA, Lindermayer JP, Buckly PJ. The medical care of patients with psychiatric illness. Hosp Community Psychiatry 1980; 31: 463-72.

23. Rentmeester CA. Postcolonial Bioethics: A Lens for Considering the Historical Roots of Racial and Ethnic Inequalities in Mental Health. Camb Q Healthc Ethics 2012; 21: 366-74.
24. Committee on Crossing the Quality Chasm: Adaptation to Mental Health and Addictive Disorders. Improving the Quality of Health Care for Mental and Substance Use Conditions. National Academies Press: Washington, DC; 2006.

25. Mitchell JB, Dickey B, Liptzin B, Sederer LI. Bringing psychiatric patients into the Medicare prospective payment system: Alternatives to DRGs. Am J Psychiatry 1987; 144: 610-5.

26. Rentmeester CA. Should a Good Healthcare Professional Be (at Least a Little) Callous? J Med Philos 2007; 32: 43-64.

27. Rentmeester CA. Moral Damage to Healthcare Professionals and Trainees: Legalism and other Consequences for Patients and Colleagues. J Med Philos 2008; 33: 27-43.

28. Bermudes RA, Keck PE, Welge JA. The prevalence of the metabolic syndrome in psychiatric inpatients with primary psychotic and mood disorders. Psychosomatics 2006; 47: 491-7.

29. Consensus Development Conference on Antipsychotic Drugs and Obesity and Diabetes. Diabetes Care 2004; 27: 596-601.

30. Casey DE, Haupt DW, Newcomer JW, Henderson DC, Sernyak MJ, Davidson $\mathrm{M}$, et al. Antipsychotic-induced weight gain and metabolic abnormalities: implications for increased mortality in patients with schizophrenia. J Clin Psychiatry 2004; 65: 4-18.

31. Marder SR, Essock SM, Miller AL, Buchanan RW, Casey DE, Davis $\mathrm{JM}$, et al. Physical health monitoring of patients with schizophrenia. Am J Psychiatry 2004; 161: 1334-49.

32. Citrome L, Blonde L, Damatarca C. Metabolic Issues in Patients with Severe Mental Illness. South Med J 2005; 98: 714-9.

33. Goldenberg D, Holland J, Schachter S. Palliative care in the chronically mentally ill. Handbook of psychiatry in palliative medicine. Oxford University Press: New York; 2000. pp. 91-6.

34. Summergrad P, Hackett TP. Alan Gregg and the rise of general hospital psychiatry. Gen Hosp Psychiatry 1987; 9: 439-45. 